\title{
Growth and characterization of La0.7Na0.3MnO3 thin films prepared by pulsed laser deposition on different substrates
}

\begin{abstract}
Perovskite manganite $\mathrm{La} 0.7 \mathrm{Na} 0.3 \mathrm{MnO} 3$ thin films were directly grown on $\mathrm{MgO}\left(\begin{array}{lll}1 & 0 & 0\end{array}\right), \mathrm{Si}(1$ 00 ) and glass substrates by pulsed laser deposition. From the XRD patterns, the films are found polycrystalline single-phases rhombohedral. The surface appears porous and cauliflower-like morphology for all LNMO films. LNMO films deposited on the glass substrate were presented smooth morphologies of the top surfaces as compared with other films. The highest magnetoresistance value obtained was $-18.86 \%$ for $\mathrm{LNMO} / \mathrm{MgO}$ films at $80 \mathrm{~K}$ in a $1 \mathrm{~T}$ magnetic field. Phase transition temperature is $221 \mathrm{~K}$ for $\mathrm{LNMO} / \mathrm{Cg}, 214 \mathrm{~K}$ for $\mathrm{LNMO} / \mathrm{Si}$ and $144 \mathrm{~K}$ for films deposited on $\mathrm{MgO}$ substrates. The films exhibit ferromagnetic transition at a temperature around $286 \mathrm{~K}$ for $\mathrm{LNMO} / \mathrm{MgO}, 304 \mathrm{~K}$ for $\mathrm{LNMO} / \mathrm{Si}$ and $292 \mathrm{~K}$ for $\mathrm{LNMO} / \mathrm{Cg}$ thin film. The Curie temperature of LNMO films deposited on the glass substrate, $292 \mathrm{~K}$ is the highest value that is reported in literature for LNMO films deposited on low-cost amorphous substrates.
\end{abstract}

Keyword: Thin films; Vapor deposition; Crystal growth; X-ray diffraction 